\title{
Social Work Practice Innovations: Helping Clients Understand, Explore, and Develop Their Friendships
}

\author{
Rich Furman \\ Kathryn Collins \\ Janet Swanson
}

\begin{abstract}
This article demonstrates the importance of helping dients understand, explore, and develop friendships in social work practice. Thenature of friendships is explored. A cross-disciplinary analysis of the literature concerning friendships and their relationship to human health and functioning is discussed. Case examples illustrating the importance of friendships and examples of the conscious use of friendships as a target of intervention are provided.
\end{abstract}

Keywords: Friendship, social support, social work practice

T he importance of relationships as a crucial factor to human well being, growth, and change has been a central theme of social work practice and research (Krill, 1969; Saleebey, 2001; Shulman, 1984). Families are recognized as central to emotional health (Carter \& McGoldrick, 1999; Janzen \& Harris, 1997; Werner, 1987), while supportive communities have been shown to be of nearly equal importance (Homan, 1999; Netting, Kettner \& McMurtry, 1998; Weil \& Gamble, 1995). While social work has done an admirable job of highlighting the necessity of family, community, and other social support relationships, the importance of friendships has been largely ignored in social work practice literature. This is lamentable since supportive friendships have been shown to be essential for psychosocial development (Clark \& Ayers, 1991; Hartup, 1979, 1983 \& 1989; Hutter, 2001; Linden, 2003; Roff, 1963), school and social functioning (Flannagan \& Bradley, 1999), emotional health (Asher \& Paquette, 2003), and lead to resiliency in many client populations (Berndt, 1989; Fraser, 1997; Miller \& Fritz, 1998). As managed care and privatization have led to sharp decreases in the number and scope of services for many clients (Dorwart \& Epstein, 1993; Dumont, 1996), social workers must rely on different types of natural social supports in helping restore clients to equilibrium and optimal functioning.

Rich Furman, MSW, Ph.D. is Assistant Professor, School of Social Work, University of Nebraska-Omaha. Omaha, NE 68182. Kathryn Collins Ph.D. is Assistant Professor, School of Social Work, University of Pittsburgh, Pittsburgh, PA 15260. Janet Swanson, BS is MSW Intern, Colorado State University, Fort Collins, CO 80523. 
This paper demonstrates the importance of helping clients understand, explore, and develop friendships as social work practice intervention. This will be accomplished in three ways. First, the nature of the client's friendships will be explored. Second, a cross-disciplinary analysis of the literature concerning friendship and its relationship to human health and functioning will be discussed. Third, case examples illustrating the importance of friendships and examples of the conscious use of friendships as a target of intervention will be provided.

\section{WHYIS FRIENDSHIP IMPORTANT IN SOCIAL WORK PRACTICE?}

In keeping with the profession of social work's unique and historic dual focus on person-in-environment, this paper advocates practices congruent with the ecological perspective. This perspective enables one to simultaneously focus on person and environment and their reciprocal relationship. According to Germain and Gitterman (1996), social work interventions that adhere to the ecological perspective recognize that causality in social work practice is reciprocal rather than linear in nature.

Beginning with the initial contact with a client, social work practitioners have the distinctive ability to help clients understand, explore, and develop friendships with individuals within their social environment in order to promote health and well being and to prevent and/or resolve psychosocial problems. For example, throughout the engagement and assessment process of working with individuals, families, groups, and communities, the concepts of friendships, interpersonal relationships, informal/formal networks, and social support should be explored with the client. This process helps the client begin to understand that facilitating friendships draws upon the strengths that exist within themselves and in their homes, schools, neighborhoods, work environments, and larger communities. Social workers already trained in tapping into the resources of family and community would be well served to increase their ability to help clients' understand and utilize friendships as a means of helping people meet their needs. Friendships help people learn about and validate themselves and provide the courage to face life's challenges.

\section{THE NATURE OF FRIENDSHIPS}

In the United States today, nuclear family relationships are prized above all other social connections. The expression "blood is thicker than water" demonstrates the place of importance that such relationships hold. In spite of the centrality of the family, close friendships may often be as or more important to people's emotional well being than are families.

Merely defining the concept of friendship is a difficult task. White and White (1982) surveyed 300 adults age 18 to 82 years regarding friendships. They concluded that there is little clear agreement about the definition of friendship; so much depended on the experiences of participants regarding friendship itself. Based on their interviews, White and White developed a model of the attributes that form the building blocks of friendship. These includelove, deep sharing, selfsacrifice, encouragement, stimulation, loyalty, and fun. Fox, Gibbs and 
Auerbach's (1985) conceptualization of friendship was comprised of slightly different variables, including altruism (mutually helping each other), companionship (enjoying shared activity), and empathy (emotional closeness and sharing of feelings). In spite of the difficulties, definitions have been developed. Burk (1996) defines friendship as "a dynamic reciprocal relationships between two individuals" (p. 283). Wiseman (1996) defines friendships as voluntary relationships that exist primarily for personal satisfaction and enjoyment rather than the fulfillment of a particular task or goal.

In spite of the importance of friendships, they are very often undervalued in modern American society. The idiom, "we are just friends," aptly expresses a prevailing social sentiment regarding the importance of friendships (Rubin, 1985). Friendship is seen not only as qualitatively different from other types of relationships, but of less value. Research often disproves these social stereotypes. Blyth and Foster-Clark (1987) found that adolescent girls reported a same-sex friend as the most intimate relationship in their lives. Boys ranked friends third for intimacy after their parents. Relationships with siblings and other family members were consistently rated as less intimate than relationships with friends.

The nature of friendships change throughout the lifespan (Hymel, Wagner \& Butler, 1990). For example, Furman and Buhrmester (1992) observed fourth graders reported that their parents were the most frequent providers of support, but seventh graders listed parents and friends as being equally supportive. By the tenth grade, friends were listed above parents for providing support. College students still listed friends as important providers of support, but they trailed just behind mothers and romantic partners. In an earlier study, Furman and Buhrmester (1985) found that fifth and sixth graders identified friends as the greatest source of companionship and ranked them equally with parents for intimacy.

Friendships are significant to many people, though they are viewed differently from familial relationships. Davidson and Duberman (1982) provide an explanation for the difference in perception between family and friends. They found that both men and women said they did not feel dependent on their friends, yet were often conflicted over dependency issues with families. Many participants recognized the impermanence of friendship relationships compared to family ties. They reported that as long as friends could be replaced, they would be satisfied.

Berndt, Hawkins and Hoyle (1986) found that intimacy-defined as a sharing of personal information-was identified by eighth grade girls as being important in their friendships. For both boys and girls, friendships characterized by high intimacy were the most stable. For adults, intimacy was found to predict the success of newly formed friendships. Those with intimate interactions after six weeks of meeting were more likely to develop close friendships. As the relationship continued, the closeness of the friendships depended on how intimate the interactions were and not on how much time the friends spent together (Hays, 1985).

Similarity and proximity also seem to be important aspects of forming and maintaining friendships. Hays (1985) discovered that the distance between where people resided was negatively correlated to the successful development of new 
friendships. That is, the farther apart people lived, the less likely they were to effectively form a friendship. Nahemow and Lawton (1975) conducted a study in New York City public housing with a diverse mix of residents of various ages and races. The closer people lived to each other, the more likely they were to be friends. In fact, when asked to identify who their friends were, more than $80 \%$ of the respondents first named someone who lived in their building-often on the very same floor. Also, similar age and race were strongly associated with friendship development. Although some friends were of different ages and races, they always lived in the same building, so their proximity to each other seemed to mitigate those differences. Some did become friends with residents of other buildings, but only if they were the same race and were close in age. The authors subsequently theorized that people are likely to make friends with those who live close to them and reach out of their immediate space to make friends with others who are similar.

Verbrugge (1977) also discovered a relationship between similarities and the likelihood of developing friendships. He found that friends tended to be similar on such factors as age, occupation, education, and political and religious preferences. Indeed, both women and men reported sharing similar values with their friends and felt that having congruent values was important to their friendship relationships (Davidson \& Duberman, 1982). Even children tend to be friends with those who are similar to them in terms of sex, race, and academic achievement (Tuma \& Hallinan, 1979).

Researchers have sought to understand relationship dynamics that have an impact on children's friendships. It is important to note that these factors change depending upon children's age, pointing to the necessity of understanding friendship from a developmental perspective. For example, Berndt, Hawkins and Hoyle (1986) saw that competitive fourth grade friends were more stable and maintained their friendships longer than non-competitive friends, but the opposite was true for eighth graders. Seventh graders placed more importance on empathic understanding and less on mutual activities than third graders and felt that they received more empathy from their friends. As children mature, they move from competitive and activity-driven friendships to ones characterized by more emotional connectedness and intimacy. Differences were also apparent between the friendships of boys and girls. Boys were found to have larger social networks, whereas, girls were more likely to limit the size of their friendship group (Benenson, 1990; Berndt \& Hoyle, 1985; Eder \& Hallinan, 1978). Boys were more concerned with status among friends and described their peers in relation to their authority and achievements, while girls were concerned with affiliation and described their peers in terms of how nice and reciprocal they were (Benenson, 1990). Girls also expected more conventional morality (not lying or cheating), loyalty, and empathic understanding and perceived that they received more of those things in their friendships than boys. Despite those differences, both boys and girls had the same expectations and perceptions of mutual activities (Clark \& Bittle, 1992).

The nature and structure of friendship relationships also differ by gender. The commonplace view of male friendships paints a picture of relationships that 
often do not meet men's psychosocial needs. Buckner (2001) maintains that friendships between men are less intimate than are men's friendships with women or friendships between women. Elkins and Peterson (1993) discovered that men reported more satisfaction with their friendships with women than with men and had lower ideal standards for male-male friendships. It is argued that patriarchy contributes to male competitiveness, whereby, men become less likely to risk "the loss of power that closeness with another might create" (Rosen, 1999, p. 129). McAdams, Healy and Krause (1984) support this claim with their finding that men who were "power-motivated"- that is, seeking friendships in order to have influence over others-were much less likely to have dyadic (oneon-one) friendships. They tended to have more group interactions where the potential for power was greater. Men see each other more as playmates than sources of emotional support (Fox, et al., 1985). When asked to describe what is important in their friendships, men frequently emphasize shared activities (Caldwell \& Peplau, 1982; Parker \& de Vries, 1993; Sapadin, 1988). Male friendships tend to show less reciprocity (giving and receiving) than do women's (Parker $\&$ deVries, 1993). Davidson and Duberman (1982) found that men related to each other primarily on a topical level, meaning that they discussed impersonal issues rather than talking about their relationship or other personal subjects.

Women's friendships, in contrast, are frequently characterized as expressive and intimate (Caldwell \& Peplau, 1982; Fox, et al., 1985). Women place great significance on self-disclosure, empathic understanding, and connectedness in their friendships (Parker \& deVries, 1993). Davidson and Packard (1981) asked women to discuss what aspects of their friendships were therapeutic for them by contributing to personal growth, support, or change. Factors such as reciprocal expression of feelings, altruism, and communion were rated as highly therapeutic. Sapadin (1988) found that women rated their same-sex friendships higher for overall quality, intimacy, enjoyment, and nurturance than did men and emphasized the interactions between friends rather than the activities. Although this may seem to imply that women's friendships are superior to men's, Davidson and Duberman (1982) discovered that men actually reported more trust in their friendships than women, possibly because conversations between male friends tended to be less personal and therefore less "risky." In a more recent study of adolescents with a relatively small sample, Benenson and Christakos (2003) found that female friendships may be of shorter duration. Clearly, more research is needed to clarify these discrepancies.

Despite these differences, both men and women identify some of the same factors as being important in their friendships. Parker and de Vries (1993) explored people's perceptions of friendships and what they valued most in those relationships. Both men and women rated trust and authenticity as the most important features in friendships. Sapadin (1988) also found similarities between men's and women's beliefs regarding friendship. Both sexes reported that sharing and enjoying each other's company are basic to friendships. When studying friendship development, Hays (1985) found that men and women were equally as likely to develop close friends after starting college. Although women may experience more intimacy with their friends, men are just as capable of forming new friendships. Men and women also report similar numbers of friends, similar amounts 
of time spent with them, and place similar value on intimate friendships (Caldwell \& Peplau, 1982).

\section{THE IMPACT OF FRIENDSHIPS}

Research on resiliency has sought to identify factors that help an individual withstand stressful events. Resiliency factors prevent the psychosocial problems that social workers normally contend with in a remedial fashion. In her review of resiliency literature, Norman (2000) noted that having a positive relationship with at least one other person is the most important factor promoting resiliency throughout the life-span. Indeed, various studies have demonstrated the positive impact of social relationships on preventing psychosocial problems (Higgins, 1994; Rutter, 1979, 1987; Werner, 1987; Werner \& Smith, 1992; Wolin \&Wolin, 1993).

While often conceptualized as internal attributes, resilience may actually stem from children's environments (Fraser, 1997). Specifically, research has demonstrated the importance of the ability to establish and maintain friendships in the lives of children (Higgins, 1994). Children who master the ability to make and maintain friendships have enormous advantages over peers without this ability. These environmental resources serve as a protective factor against various psychosocial risks. Being part of a social network was strongly related to overall peer acceptance, especially for boys (Benenson, 1990). According to Clark and Ayers (1988), middle school students with reciprocated friendships (meaning peers they identified as friends also identified them) were viewed as more successful and attractive by their peers. Cauce (1986) looked at African-American seventh graders who came from families of low socioeconomic status. Those students who had an extensive social network displayed more social competence. Furthermore, in a study based on who children rely on when building a safety plan to avoid violence in their schools and neighborhoods, Collins (2001) found that children ages nine to 12 years stated that their friends often "stand up for them" or "protect them" from bullies.

Research has shown that supportivefriendships serveas a protective factor during times of stress (Berndt, 1989). In fact, friendships might be more important to decreasing one's stress than familial relationships. Some people are more likely to discuss stressful events with friends than families, as family members often have more expectations and judgments than friends. For example, a person who is experiencing stress over no longer being happy with his or her current work situation is more likely to receive uncritical support from a friend who has less personally at stake than from a family member who is dependent upon that person for fiscal support. In addition, families are often the very issue about which one is experiencing stress, thus, necessitating alternative social supports. Dunn, Davies, O'Connor and Sturgess (2001) found that children who had experienced a parental separation reported more positive feelings about moving between two households if they had close friendships. Those who lived with a stepmother or who were involved in conflicts between their biological parents confided in friends more often than other children.

Friendships are valuable in meeting needs that have traditionally been met within the family. As family structures have changed in American society over 
time, people often rely upon friendships to meet various psychosocial needs (Bell, 1981). Wright (1978) identified various social rewards that friendships can offer. First, a friend can be willing to help one meet needs and goals. Friends can affirm positive ideas about oneself while providing ego support-hel ping a friend see him or herself as a competent, worthwhile person. Friends can also introduce new ideas and experiences while expanding knowledge and perspectives.

Researchers have explored how friendships affect students' adjustment at school. Studies have shown that children and adolescents often exhibit behaviors that are similar to their friends-both positive and negative. Berndt and Keefe (1995) observed that as the school year progressed, students became more like their friends regarding disruption in class and grades. If a student had friends who were not disruptive and received good grades (or vice versa), he or she would tend to behave in a similar manner. Students themselves perceived that their level of disruption in school was similar to that of their friends. Friends who exhibit antisocial or deviant behavior are risk factors, while friends who are well socialized and "normatively conventional" are positive factors in development (Hartup \& Stevens, 1997).

The quality of friendships may also affect students' adjustment. Seventh and eighth graders with "positive" friendships, characterized by self-disclosure, mutual helping, and faithfulness, tended to not only have more stable, long lasting friendships, but also showed desirable social behavior and good adjustment to school. They reported more acceptance by peers and higher self-esteem (Berndt \& Keefe, 1995). In this study, students who viewed their friendships positively were rated by teachers and themselves as more involved in school. Even kindergartners tended to like school more when they perceived higher levels of aid from their friends. When boys perceived conflicts in their friendships, they showed more loneliness and avoidance and liked school less (Ladd, Kochenderfer \& Coleman, 1996). Seventh and eighth grade students who had conflict and rival ry in their friendships showed poorer adjustment to school and rated themselves as more disruptive and less involved (Berndt \& Keefe, 1995). High school students with friendships high in hostility and low in reciprocity showed more delinquent behavior, alcohol use, and depression (Windle, 1994). Even for adults, those without close friendships may be vulnerable to feelings of dysphoria and loneliness (Elkins \& Peterson, 1993; Williams \& Solano, 1983).

\section{THE PRACTICE OF HELPING CLIENTSUNDERSTAND, EXPLORE, AND DEVELOP FRIENDSHIPS}

Norman (2000) asserts that helping clients develop resiliency factors allows social workers to implement the strengths perspective. The strengths based approach to social work practice has been growing in influence over the last several decades. Based upon the literature of resiliency, the strengths perspective challenges social workers to help people utilize their skills and competencies in overcoming life's problems. Thestrengths perspective does not deny the existence of problems, but asserts that maximizing the strengths and resources of individuals and groups is the best means of helping them overcome life's challenges. Saleebey (2001) describes the strengths perspective in the following way: 
Practicing from a strengths orientation means that everything you do as a social worker (or therapist) will be predicated, in some way, on helping to discover and embellish, explore, and exploit clients' strengths and resources in the service of assisting them to achieve their goals, realize their dreams, and shed the irons of their own inhibitions and misgivings (p. 3).

Proponents of the strengths perspective recognize the importance of social supports found in communities. Cowger (1997) recognizes the importance of friendships in his strengths based assessment of clients. Workers are encouraged to explore the nature of clients' friendships, their ability to be understanding of and make sacrifices for friends, and their ability to make friends. By exploring clients' skills and resources pertaining to friendships, workers are able to help clients maximize their support and their ability to withstand life's pressures and problems.

In this section, case examples are presented in which friendships and friendship systems were a primary target of change. This does not imply that friendships were necessarily the problem but were utilized as solutions to various psychosocial stressors. Social workers can help clients meet various needs by helping them strengthen their friendship relationships.

\section{Dan: Case Example One}

Dan is a 37-year-old single male. He has worked as a computer repairperson for the last several years. Dan sought treatment for feeling isolated and depressed. He has been lonely much of the time and does not feel a sense of connectedness to others. During a previous course of treatment, Dan was placed on medication that decreased, but did not eliminate, his depression. Healso was able to improve his relationships with his family of origin and joined a book club that increased his sense of connectedness to people. He also started to date a woman whom he saw about once a week. In spite of these changes, Dan still felt somewhat depressed. While his new social contacts were important, Dan longed for more meaningful and intimate friendships.

As a child, Dan was often lonely and sad. He had few friendships and was the youngest child in a distant, detached family. The friendships that he developed as a young man in college and in the Navy provided his first reprieve from the loneliness that he felt in his life until that time. During therapy he began to realize that the close friendship bonds that heexperienced during these earlier years were the missing piece that he needed in order to feel a sense of wholeness. In spite of this realization, Dan was not certain how to go about making friends at this stage in his life or whether he wanted to do the work necessary to start a relationship. Dan was also deeply afraid of being hurt and rejected by others. Several years earlier, Dan attempted to start a friendship with a coworker at a previous place of employment. He and this other man began watching football together on Sundays and started to talk about their lives, pains, and dreams. Just as he and his new found friend were beginning to become close, his friend informed Dan that he was "strange" and did not want to be his friend anymore.

Developing meaningful and supportive friendships became a primary goal in therapy. One of the first early steps to help Dan work towards this goal was to 
point out his strengths regarding forming relationships. Collaboratively, we developed an inventory of his strengths that included being able to talk to people easily, having interesting things to say, being able to talk about his feelings, having a history of making friends, being a loyal and kind person, and having a good sense of humor. Helping Dan recognize his strengths was instrumental in helping him become more invested in the process. By focusing on his strengths and not only his deficits, Dan began to perceive himself as more socially competent and less fearful of increasing his social contacts. Soon, Dan was able to ask a fellow member of his book club out for coffee. After meeting several times for coffee, Dan stated that he believed this man would become a friend. He reported feeling less isolated and more hopeful.

During his final three months of therapy, Dan was able to explore difficulties he experienced with reconnecting to friends. For example, Dan and the above mentioned new friend had an argument over which restaurant they would have dinner at. Dan gave in to his new friend's demands but felt mistreated and resentful. He believed that the friendship would soon be over and that he would go back to being alone. Collaboratively, we explored alternative meanings for the conflict. Dan decided that the struggle with his friend really was more about the both of them being afraid of intimacy even though it manifested as being about control. Addressing the issue with his new friend allowed both of them to develop a greater sense of trust in their relationships. Dan and his new friend learned that their friendship could survive conflict and that they could be closer for it.

\section{Juanita: Case ExampleTwo}

Juanita, diagnosed with an explosive disorder and mild mental retardation, presented changes requiring a more direct, behaviorally oriented intervention. Juanita, a 17 year-old young woman, lived in a residential treatment center for troubled teens. She had been in placements of one kind or another for nearly six years. Diagnosed with intermittent explosive disorder and mild mental retardation, she became aggressive in school and ultimately at home. Her mother, who was addicted to cocaine, was not able to handle her. Juanita never knew her father. By the time she began treatment, her social network consisted solely of the staff in her group home. She was not able to make friends at her school and was thought to have very poor social skills.

Juanita possessed very negative views of friendships. She recalled a long history of experiences in group homes where other children would take advantage of her. She reported the story of a girl she knew in a prior group home who befriended her as a means of taking advantage of her. This girl "borrowed" money that she never repaid, took her belongings, and manipulated her into doing things that got her into trouble. In her mind, peers and friends led to trouble.

In spite of Juanita's negative feelings about friendship, she also desperately craved companionship from her peers. In therapy, we explored what healthy friendships were like. I utilized self-disclosure to help her believe in the possibility of healthy, supportive friendships. I also asked the counselors in the group home to talk about their friendship. Over the next two or three weeks, Juanita developed a sense of openness to the possibility of a friendship. 
Asked if there were any people currently in her life that she would like to befriend, Juanita mentioned one girl in her class at school. She reported that while she enjoyed this girl's company at times, they would often quarrel and could not figure out how to get along. Juanita also mentioned that it was hard to really get to know the other girl in the confines of a highly structured school setting. With encouragement, Juanita decided that she would invite this girl (Amy) over for dinner during the weekend, when many of the other teens who lived at the group home were visiting with family.

I contacted the school social worker and found out that Amy lived in another group home a few miles away. Juanita called Amy and asked her if she would like to have dinner the following weekend. Amy said she would love to and that she and Juanita would discuss plans the following day. Juanita put me on the telephone, and I asked Amy if I could discuss arrangements and details with the social worker in the group home. I informed Amy that I wanted to learn enough about her and what she liked to help her and Juanita have a good experience. She agreed.

The following day I spoke with Amy's social worker, whom she saw for individual and group therapy. We discussed both girls' likes and dislikes, their strengths, and issues that might lead to conflict. We subsequently made specific travel arrangements. Later that night, Juanita informed me that she and Amy decided that they would like to have spaghetti and watch a movie about animals. Juanita and I also processed the conflicts that she and Amy had in advance and worked out ways of resolving potential disagreements. Before their evening together, I met with Juanita to discuss potential problems that could occur. She was most worried about not being able to share and compromise with Amy. We subse quently role played several scenarios, allowing Juanita to practice sharing and compromise. She was able to do this easily. I validated her good communication skills and helped her see that she indeed was able to do things she worried about not being able to do.

On the evening that Amy was to come over, I made plans to be in the group home but agreed to stay in the therapy room unless I was needed. The evening that Amy spent with Juanita went smoothly. They had one disagreement during which Juanita suggested they both come and speak to me. I was able to help them compromise in regard to what games they would play and when and helped them work on their negotiating skills. Amy and Juanita started to spend more time together at school, and subsequently spent one or two days a week together. Over time, Juanita began to learn that while friendships were often difficult and demanded hard work, they did not have to end in her being manipulated. Over time, her relationships with other children in the group home improved and she felt less isolated and depressed.

\section{IMPLICATIONS FOR SOCIAL WORK PRACTICE}

We have highlighted some of the unique aspects of the importance of helping clients understand and develop friendships in their social network. Increasing research evidence suggests that individuals who have a sense of belonging within their social environment through the use of friendships have greater self- 
esteem, stability, and well being. Consequently, social work practitioners should routinely inquire about a client's history of interpersonal relationships, their motivation to continue or develop ties with others as friends and supporters, and gain an understanding of how these relationships can benefit the client within current and future life situations.

Often times, the intervention of helping clients understand, explore, and develop friendships begins at the first meeting with the social worker. It is interesting that in just about every "pop culture" magazine the topic of "how to be or make a friend" is covered, yet social workers often forget the importance of exploring skills within the interventions we provide in our service to clients. Social workers teach clients how to network within their community to obtain appropriate services and resources, but often do not help clients find and develop intimate and supportive friendships outside of the social service or health systems. Social workers can provide role modeling through using the unique skills of engagement strategies such as empathic listening, attending, and being genuine with clients. The "therapy office" is the microcosm of the broader society. However, one must not confuse professional boundaries of the social support of the helping professional as friendship. Social workers realize that, as a helping professional, it is of no use to our client to also be their friend if we are to maintain a supportive, therapeutic alliance. Instead, we help to instill the skills of friendship through problem solving on how/where to find friendships, role play on how clients may engage potential friends or develop more meaningful relationships with friends, and develop skills on improving communication patterns.

Social workers can teach families how they can help children and young adults develop friendships. For example, parents/guardians may want to create a home environment that is attractive to their family member's social network by inviting classmates, church group members, or club members to the home for an informal or formal function. Families can identify local community places where children and young adults typically "hang out" and/or encourage youth to become involved in community groups and activities with their peers. This will provide repeated opportunities for children and young adults to become active and meet new peers. Just as social workers can review the process of developing friendships with adult clients, they can also use role-playing and problem solving for younger clients.

Social service agencies may consider creating connections among clients and between clients and community by implementing "club forums." Club forums are a way for community members to unite around particular issues or situations within the community. This helps to de-stigmatize and de-mystify the mission of social service agencies within the community while providing an opportunity for interpersonal relationships and friendships to develop through a process of mutual interest.

It is the hope of these authors that social worker practitioners and social work educators have been challenged and inspired by this article to further explore the ways in which friendships can help enrich the lives of our clients. 


\section{References}

Asher, S.R., \& Paquette, J.A. (2003). Loneliness and peer relations in childhood. Current Directions in Psychological Science, 12(3), 75-79.

Bell, R.R. (1981). World of friendships. Beverly Hills, CA: Sage.

Benenson, J.F. (1990). Gender differences in social networks. Journal of Early Adolescence, 10(4), $472-495$.

Benenson, J.F., \& Christakos, A. (2003). The greater fragility of female verses male closest same-sex friendships. Child Development, 74(4), 1123-1130.

Berndt, T.J. (1989). Obtaining support from friends in childhood and adolescence. In E. Bell (Ed.), Children's social networks and social supports. New York: Wiley.

Berndt, T.J., Hawkins, J.A., \& Hoyle, S.G. (1986). Changes in friendship during a school year: Effects on children's and adolescents' impressions of friendship and sharing with friends. Child Development, 57, 1284-1297.

Berndt, T.J., \& Hoyle, S.G. (1985). Stability and change in childhood and adolescent friendships. Developmental Psychology, 21(6), 1007-1015.

Berndt, T.J., \& Keefe, K. (1995). Friends' influence on adolescents' adjustment to school. Child Development, 66, 1312-1329.

Blyth, D.A., \& Foster-Clark, F.S. (1987) Gender differences in perceived intimacy with different members of adolescents' social networks. Sex Roles, 17, 689-718.

Buckner, D.R. (2001). Masculinity, gender role conflict, and male-male friendships. Doctoral Dissertation. Dissertation Abstracts International. Section B,.62 (3-B).U.S: University Microfilms International.

Burk, D.I. (1996). Understanding friendship and social interaction. Childhood Education, 72(5), 22-32.

Caldwell, M.A., \& Peplau, L.A. (1982). Sex differences in same-sex friendships. Sex Roles, 8(7), 721-732.

Carter, B., \& McGoldrick, M. (1999). Theexpanded family lifecycle: Individual, family and social perspectives. ( $3^{\text {rd }}$ ed.). Boston, MA: Allyn \& Bacon.

Cauce, A.M. (1986). Social networks and social competence: Exploring the effects of early adolescent friendships. American Journal of Community Psychology, 14(6), 607-628.

Clark, M.L., \& Ayers, M. (1988). The role of reciprocity and proximity in junior high school friendships. Journal of Youth and Adolescence, 17(5), 403-411.

Clark, M.L., \& Ayers, M. (1991). Friendship similarity during adolescence: Gender and racial patterns. The Journal of Psychology, 126(4), 393-405.

Clark, M.L., \& Bittle, M.L. (1992). Friendship expectations and the evaluation of present friendships in middle childhood and early adolescence. Child Study Journal, 22(2), 115-135.

Collins, K.S. (2001). Children's perceptions of safety and exposure to violence. International Journal of Adolescenceand Youth, 10(1-2), 31-49.

Cowger, C. (1997). Assessing client strengths: Assessment for client empowerment. In E. Saleebey (Ed.). Thestrengths perspectivein social work. (pp. 59-73). New York: Longman.

Davidson, L.R., \& Duberman, L. (1982). Friendship: Communication and interactional patterns in samesex dyads. Sex Roles, 8(8), 809-822.

Davidson, S., \& Packard, T. (1981). The therapeutic value of friendship between women. Psychology of Women Quarterly, 5(3), 495-510.

Dorwart, R.A., \& Epstein, S.S. (1993). Privatization and mental health care: A fragile balance. Westport, Connecticut: Auburn House.

Dumont, M.P. (1996). Privatization and mental health in Massachusetts. Smith College Studies in Social Work, 66(3), 293-303.

Dunn, J., Davies, L.C., O'Connor, T.G., \& Sturgess, W. (2001). Family lives and friendships: The perspectives of children in step-, single-parent, and non-step families. Journal of Family Psychology, 15(2), 272287. 
Eder, D., \& Hallinan, M.T. (1978). Sex differences in children's friendships. American Sociol ogical Review, $43,237-250$.

Elkins, L.E., \& Peterson, C. (1993). Gender differences in best friendships. Sex Roles, 29(7/ 8), 497-508.

Flannagan, D., \& Bradley, L. (1999). Judging the behaviors of friends and unfamiliar peers: Patterns associated with age and gender. Journal of Early Adolescence, 19(3), 389-404.

Fox, M., Gibbs, M., \& Auerbach, D. (1985). Age and gender dimensions of friendship. Psychology of Women Quarterly, 9, 489-502.

Fraser, M.W. (1997). Risk and resilience in childhood: An ecological perspective Washington, D.C.: National Association of Social Workers Press.

Furman, W., \& Buhrmester, D. (1985). Children's perceptions of the personal relationships in their social networks. Developmental Psychology, 21(6), 1016-1024.

Furman, W., \& Buhrmester, D. (1992). Age and sex differences in perceptions of networks of personal relationships. Child Development, 63, 103-115.

Germain, C.B., \& Gitterman, A. (1996). The life model of social work practice: Advances in theory \& practice. (2 ${ }^{\text {nd }}$ ed.). NY: Columbia University Press.

Hartup, W.W. (1979). Peer relations and growth of social competence. In M.W. Kent \& J.E. Rolf (Eds.), Primary prevention of psychopathology, Vol. 3., Lebanon, NH: University Press of New England.

Hartup, W.W. (1983). Peer relations. In P.H. Mussen (Ed.), Handbook of child psychology. (4 ed., Vol. 4). New York: Wiley.

Hartup, W.W. (1989). Social relationships and their developmental significance. American Psychologist, 44, 120-126.

Hartup, W.W., \& Stevens, N. (1997). Friendships and adaptation in the life course. Psychological Bulletin, 121(3), 355-370.

Hays, R.B. (1985). A longitudinal study of friendship development. Journal of Personality and Social Psychology, 48(4), 909-924.

Higgins, G.O. (1994). Resistant adults: Overcoming a cruel past. San Francisco: Jossey-Bass.

Homan, M.S. (1999). Promoting community change: Making it happen in the real world. (2 $2^{\text {nd }}$ ed.). Pacific Grove, CA: Brooks/Cole.

Hutter, H. (2001). On friendship. Contemporary Sociology, 30(6), 579-581.

Hymel, S., Wagner, E., \& Butler, L.J. (1990). Reputational bias: View from the peer group. In S.R. Asher, \& J.D. Coie (Eds.), Peer rejection in childhood (pp. 156-189). New York: Cambridge University Press.

Janzen, C., \& Harris, O. (1997). Family treatment in social work. (3rd edition). Itasca, IL. F.E. Peacock.

Krill, D. (1969). Existential psychotherapy and the problem of anomie. Social Work, 14(2), 33-49.

Ladd, G.W., Kochenderfer, B.J., \& Coleman, C.C. (1996). Friendship quality as a predictor of young children's early school adjustment. Child Development, 67, 1103-1118.

Linden, G.W. (2003). Friendship. Journal of Individual Psychology, 59(2), 156-166.

McAdams, D.P., Healy, S., \& Krause, S. (1984). Social motives and patterns of friendship. Journal of Personality and Social Psychology, 47(4), 828-838.

Miller, M., \& Fritz, M .F. (1998). A demonstration of resilience. Intervention in School and Clinic, 33, 25-32.

Nahemow, L., \& Lawton, M.P. (1975). Similarity and propinquity in friendship formation. Journal of Personality and Social Psychology, 32(2), 205-213.

Netting, J.E., Kettner, P.M., \& McMurtry, S.L. (1998). Social work macro practice New York: Longman.

Norman, E. (2000). Resiliency enhancement: Putting the strengths perspective into social work practice. New York: Columbia.

Parker, S., \& deVries, B. (1993). Patterns of friendship for women and men in same and cross-sex relationships. Journal of Social and Personal Relationships, 10, 617-626.

Roff, M. (1963). Childhood social interactions and young adulthood psychosis. Journal of Clinical Psychology, 19,152-157. 
Rubin, L.B. (1985). Just friends. The role of friendships in our lives. New York: Harper \& Row.

Rutter, M. (1979). Protective factors in children's responses to stress and disadvantage. In M.W. Kent \&J. Rolf (eds.), Primary prevention of psychopathology, Vol.3: Social competence in children, (pp. 49-74). Hanover, $\mathrm{NH}$ : University of New England.

Rutter, M. (1987). Psychosocial resilience and protective mechanisms. American Journal of Orthopsychiatry, 57(3), 316-331.

Saleebey, D. (2001). Thestrengths perspectivein social work practice ( $2^{\text {nd }}$ ed.). New York: Longman.

Sapadin, L.A. (1988). Friendship and gender: Perspectives of professional men and women. Journal of Social and Personal Relationships, 5, 387-403.

Shulman, L. (1984). Theskills of helping individuals and groups (2nd ed.). Itasca, IL: Peacock.

Tuma, N.B., \& Hallinan, M.T. (1979). The effects of sex, race, and achievement on schoolchildren's friendships. Social Forces, 57(4), 1265-1285.

Verbrugge, L.M. (1977). The structure of adult friendship choices. Social Forces, 56(2), 576-597.

Weil, M., \& Gamble, D.N. (1995). Community practice models. In TheEncyclopedia of Social Work (19 ${ }^{\text {th }}$ ed. Vol. 1, 577-93). Washington, D.C.: National Association of Social Workers.

Werner, E.E. (1987). Vulnerability and resiliency in children at risk for delinquency: A longitudinal study from birth to young adulthood. In J. Burchard and S. Burchard (Eds.), Prevention of delinquency behavior, (pp. 16-43). Newbury Park, CA: Sage.

Werner, E.E., \& Smith, R.S. (1992). Overcoming the odds: High risk children from birth to adulthood. Ithaca, NY: Cornell University Press.

White, J., \& White, M. (1982). Friends and friendship: The secrets of drawing doser. Colorado Springs, CO: Navpress.

Williams, J.G., \& Solano, C.H. (1983). The social reality of feeling lonely: Friendship and reciprocation. Personality and Social Psychology Bulletin, 9(2), 237-242.

Windle, M. (1994). A study of friendship characteristics and problem behaviors among middle adolescents. Child Development, 65, 1764-1777.

Wiseman, J.P. (1996). Friendship: Bonds and binds in voluntary relationships. Journal of Social and Personal Relationships, 3(2), 191-211.

Wolin, S.J., \& Wolin, S. (1993). The resilient self: How survivors of troubled families rise above adversity. New York: Villard Books.

Wright, P.H. (1978). Toward a theory of friendship based on a conception of self. Human Communication Research, 4(3), 196-207.

\section{Author's Note:}

Address correspondence to: Rich Furman, MSW, Ph.D., Assistant Professor, School of Social Work, University of Nebraska-Omaha, $60^{\text {th }}$ and Dodge Streets, Omaha, NE 68182, USA. E-mail: rfurman@mail.unomha.edu 